\title{
Entrevistas fingidas: a propósito de un texto sobre la princesa Letizia
}

\author{
Juan CANTAVElla Blasco \\ Universidad CEU San Pablo \\ jcantavella@ceu.es
}

Recibido: 2 de septiembre de 2014

Aceptado: 10 de marzo de 2015

\begin{abstract}
Resumen
La publicación de una entrevista imaginaria con la entonces princesa Letizia en la revista Diez Minutos provocó una reacción crítica en las redes sociales y en algún medio periodístico. Una asociación profesional llevó el tema ante la Comisión Deontológica de la Federación de Asociaciones de la Prensa. El autor de este artículo redactó un dictamen a petición de la revista, donde exponía que existe una larga tradición de entrevistas fingidas, que a estas alturas no puede ser motivo de escándalo, siempre que se diga, como en esta ocasión, que no se trata de respuestas verdaderas, sino imaginadas en base al sentido común y a lo que siempre suele responder en los diálogos conocidos la ahora Reina de España. La Comisión dictó una resolución en la que, sin descalificar por completo a la revista, no acepta su actuación en este caso. Palabras clave: Entrevista, prensa, deontología.
\end{abstract}

\section{Mock interviews: a text about Princess Letizia}

\begin{abstract}
The publication of a fake interview with former time princess Letizia in the Diez Minutos magazine provoked a critical reaction from the social media and from other newspapers. A professional association took up the issue to the Comisión Deontológica de la Federación de Asociaciones de la Prensa. Asked by the magazine, the author of this article wrote a legal report, where he stated that there is a long tradition of fake interviews, and so they cannot be considered as something wrong, if they are presented, as it was the case, as not the real answers, but just made up or fake answers according to what today's Queen of Spain usually answers when she has been asked the same and also according to the common sense. The verdict of the Deontologic Commission was rejecting the interview, although not fully blaming the magazine.
\end{abstract}

Keywords: Interviews, press, deontologie.

\section{Referencia normalizada}

CANTAVELLA BLASCO, Juan (2015): "Entrevistas fingidas: a propósito de un texto sobre la princesa Letizia". Estudios sobre el Mensaje Periodístico. Vol. 21, Núm. 2 (julio-diciembre), págs.: 987-1002. Madrid, Servicio de Publicaciones de la Universidad Complutense.

Sumario: 1. Planteamiento. 2. Algunas muestras. 3. No existe engaño. 4. Entrevistas falsas y entrevistas fingidas. 5. Datos de una encuesta. 6. Referencias bibliográficas. 7. Anexo: Resolución 2014/95 de la Comisión de Arbitraje, Quejas y Deontología del Periodismo (FAPE).

\section{Planteamiento}

Con fecha de 28 de mayo salía a la calle el número 3.275 del popular semanario Diez Minutos: en portada y en páginas interiores destacaba el hecho de que se cumplieran diez años del matrimonio de la periodista Letizia Ortiz Rocasolano con el Príncipe de Asturias, Felipe de Borbón. Además de la foto de portada y veinte imágenes seleccionadas en el interior, se anunciaba la inclusión de una "entrevista imaginaria". Es la que ocupa las páginas 10 a 13 y la redacción insiste en presentarla como "entrevista imaginaria", apoyando esta forma de designarla con una especie de antetítulo que rezaba: 
"Recreamos con datos contrastados y documentación fiable la conversación que podría haber tenido con nuestra revista". Está firmada por D. M., lo que puede ser interpretado como un equipo que utiliza las iniciales de la revista para darle mayor consistencia.

A pesar de que presentan este texto sin escudarse en medias verdades, se produjeron algunas reacciones que no dejan de llamar la atención. Por una parte, el Colegio de Periodistas de Murcia solicitó que la Fundación Comisión de Arbitraje, Quejas y Deontología de la Federación de Asociaciones de la Prensa examinara el contenido de este texto, pues a su juicio supone un "descrédito" para la profesión al atacar "los principios generales de la deontología profesional". Por otra, el diario El País tomó una actitud beligerante, dado que el 16 de junio publicaba una información titulada "La frontera entre periodismo y ficción" (p. 21) y al día siguiente un comentario editorial sobre "Entrevistas inventadas" (p. 30). A la vista de esta situación, la directora de la revista, Cristina Acebal, me solicitaba un dictamen sobre si se suelen publicar este tipo de entrevistas, pues tenía el convencimiento de que existe una tradición consolidada en la prensa española en dicho sentido y que no se engaña a nadie cuando se la presenta abiertamente como lo que es, una "entrevista imaginaria".

Mi respuesta no podía ser otra que confirmar su impresión inicial. Y para ello aportaba una autocita: "Existe otra modalidad de entrevista periodística que ha tenido una tradicional aceptación en la prensa escrita y, pese al tiempo transcurrido, continúan apareciendo muestras inteligentes y vigorosas que ponen de manifiesto su asentamiento y su adaptación a los tiempos presentes. Nos referimos a la entrevista fingida: aquella que podría ser real, pero no lo es; la que toma las formas de esta clase de textos y está dotada de una verosimilitud que la hace creíble, pero en verdad no ha tenido lugar y en algunos casos es imposible que tal suceda. El personaje elegido, la indicación con que se encabeza o el espacio donde aparece, declaran paladinamente que nos encontramos ante una apariencia de entrevista". Con estas palabras empieza el epígrafe dedicado a la entrevista fingida en mi Manual de la entrevista periodística (2007: 83) dentro de las diversas modalidades de textos conversacionales que son práctica habitual en los medios impresos.

Tal clasificación se formula por primera vez en mi tesis doctoral (1994) ${ }^{1}$, se expone en el citado manual cuando aparece la primera edición en 1996 y a continuación ha sido recogida por otros autores, aquellos que ofrecen un panorama de las distintas formas de entrevistas que se pueden realizar y con las que se pueden encontrar los lectores. Por ejemplo, se refieren a ella - con constantes citas de mi libro- Balsebre, Mateu y Vidal en La entrevista en radio, televisión y prensa: "Heredera directa de las escenas dialogadas satíricas o de los cuadros de costumbres que aparecieron prolijamente en las publicaciones periódicas del XIX, la entrevista fingida con personajes inventados o con declaraciones inventadas de personajes reales constituye una longeva modalidad de la entrevista periodística escrita" (1998: 321), a lo que añaden que "las entrevistas falsas o fingidas se incardinan tanto en el gusto del periodismo moderno que incluso en la prensa clandestina española -y singularmente en la catalana- aparecen numerosos ejemplos de ellas en los años 30 y 40 [del siglo XX, claro]". Es importante la dis-

1 Defendida en la Universidad Complutense y calificada con "sobresaliente cum laude". Recibió a continuación el Premio Extraordinario del Doctorado. 
tinción que aportan, pues señalan que entre los textos de esta naturaleza hay algunos que tratan de dar respuestas verosímiles en línea con lo que es la trayectoria del personaje, mientras que en otros casos se acentúa el carácter satírico, al deformar o exagerar voluntariamente lo que podrían ser sus opiniones, con el resultado de conformar una especie de caricatura. De ambas derivaciones hay numerosas muestras.

Esta modalidad entra igualmente en la clasificación aportada por José Rodríguez Vilamor, junto con otras muchas que se pueden detallar (2000: 373), así como en el libro de Begoña Echevarría (2002: 22) y en el de Miriam Rodríguez Betancourt. En este último leemos: "Otro tipo de entrevista empleada en ocasiones -quizás demasiado a menudo- es la imaginaria o de ficción que puede ir desde 'poner a hablar' a un objeto inanimado, hasta 'conversar' con un personaje histórico. En revistas y espacios similares, elaboradas con gusto y ponderación, pueden resultar atractivas" (2001: 31). Bien es verdad que esta introduce algunos peros a continuación: "Sin embargo, cuando se las emplea como recurso facilista se puede caer en el grave error de presentar como válido y real algo que no lo es y en periodismo, es decir, en esa forma como se "representa la realidad", no es válido. Cabe la posibilidad de que la audiencia, ya sea de prensa, radio o televisión, lo tome como real" (ibídem).

No se trata, por tanto, de una aportación tan exótica cuando comprobamos que forma parte de las clasificaciones que se manejan en los libros de texto para los estudiantes de Periodismo. Las muestras son ciertamente abundantes en los periódicos y algunas las veremos a continuación. Un seguimiento de los periódicos antiguos nos haría comprobar la frecuencia con que aparecen. En ningún caso se nos ocurriría presentar una relación exhaustiva de todas las entrevistas de este género que hemos encontrado en los medios escritos, ya que podemos asegurar que no son pocas, como tampoco son escasos los libros que han utilizado esta técnica y la ofrecen a sus lectores (unas veces habiendo pasado previamente por los periódicos y otras directamente, como tantas modalidades periodísticas que han sido aprovechadas para otros fines: diálogos, reportajes...). Tengamos en cuenta que la entrevista llega a España en la década de los ochenta del siglo XIX y, con las de declaraciones y las de personalidad, que son las más frecuentes y demandadas, pronto nos vamos a encontrar con otras bien distintas. Nos referimos a las semblanzas, las de cuestionario fijo, las fingidas o las de carácter lúdico, que es la última que se ha incorporado. Esta variedad da idea del desarrollo que ha tenido el género y de la aceptación popular que conlleva.

\section{Algunas muestras}

Veamos algunas muestras que ilustran nuestro planteamiento. En aquellos estadios iniciales nos encontramos que el semanario Blanco y Negro (que nace en 1891) iba publicando en cada número una página bajo la rúbrica de "Lo que dicen las estatuas". En una de ellas, por ejemplo ${ }^{2}$, se ocupa de conocer las supuestas opiniones del pintor Murillo, que preside una de las plazas que se hallan cerca del Museo del Prado, en Madrid. El autor comienza con una justificación, pues "el director de Blanco y Negro me ha encomendado la para mí honrosa misión de interviewaros, como decimos ahora, por

2 Balsa de la Vega, R: "La de Murillo", en Blanco y Negro, 20 de noviembre de 1892, pp. 20 y 21 . 
no decirlo en castellano, que sería mucho más fácil y comprensible; por lo tanto, estoy a las órdenes de vuesamerced, y soy todo oídos, si es que tenéis la bondad de decirme algo de lo mucho que, indudablemente, habéis meditado acerca de la cosa artística". Años después aparecían unas "Interviews populares" firmadas por Ginés de Pasamonte ${ }^{3}$. En una de sus entregas (1898) conversaba con la Estatua de la Libertad, otra con el cerdo de San Antón, con Bernardo (el de la espada) o con Juan Palomo. Son figuras míticas, animales o estatuas a las que evidentemente no se puede interrogar y, por tanto, pertenecen al género de la ficción. Y aún el humorista Juan Pérez Zúñiga escribe una "Interview con una foca" . En ninguno de los casos citados se apostilla el texto con que se trata de una entrevista imaginaria, dadas las nulas posibilidades de que un lector se viera confundido.

Más casos antiguos. El diario gallego El Noroeste publica una supuesta entrevista de Wenceslao Flórez con el ex ministro Sánchez de Toca expuesta en clave de humor ${ }^{5}$ y del mismo estilo está dotada la que González-Ruano presenta con el también ex ministro Santiago Alba ${ }^{6}$. Cuando este rechaza el mantener una conversación con el periodista, añade aquél: "Punto, pues, boca mía. Punto sobre tus plumas, miserable pluma mía. Pero punto y coma, esto sí; porque a mí ni don Santiago ni Sant-Yago me pueden impedir que reconstituya esta desangelada escena de la interviú fracasada... que ha llegado al tamaño aproximado que tienen todas las interviús. Y, sin embargo, don Santiago, iqué poco trabajo le hubiera a usted costado que hubiéramos tenido la siguiente conversación!: - ¿Va usted a reorganizar el partido que licenció? Y el señor Alba me hubiera contestado indefectiblemente..." (2002: 187).

En el mundo profesional era bien conocido Manuel del Arco, zaragozano que fue relegado a Barcelona tras la guerra civil. Su entrevista recuadrada y con una caricatura, también de su autoría, no podía faltar cada día en La Vanguardia Española. Y efectivamente se esforzaba por conversar con el personaje público que era noticia por su llegada a la ciudad. Pero, entre los miles de diálogos que publicó es posible encontrar algunos que nadie daría por reales. Es el caso de la que efectúa al "último nacido sobre la tierra". O sea, su hija en el instante de nacer: "Un personaje que en honor a la verdad me ha dado menos lata que ningún otro. Aunque a partir de ahora me hará andar de coronilla" (en ningún momento se dice que se trata de un fingimiento o ¿es que hacía falta decirlo?). Años después confesaba que era la "interviú" que más le gustó: "Desde luego ninguna la hice con tanto cariño" (Arco, 1960a: 413-414) ${ }^{7}$. No

3 Probablemente un seudónimo, puesto que no figura en el catálogo de periodistas de Ossorio ni en el de López de Zuazo.

418 de mayo de 1901 (número 524). Con ilustraciones de Xaudaró.

5 Fue el 22 de marzo de 1913. Ha sido reproducida en José M. Paz Gago (ed.): 125 aniversario del nacimiento de Wenceslao Fernández Flórez. A Coruña, Asociación de la Prensa, 2010, pp. 84-86.

6 Puede verse en González-Ruano: “Una interviú con don Santiago Alba”, en Nuevo Mundo, 27 de marzo de 1931 (también en 2002: 186-188).

7 En esa ocasión fue su hija Olga la "entrevistada", pero años después repitió el mismo esquema con su hijo Manolico, por cierto con una acusada falta de imaginación (1960b: 544-545). 
fue la única, porque en otra ocasión "habló" con los tres reyes magos cuando desembarcaban un 5 de enero en el puerto de Barcelona.

Para entrevista no fingida, sino absolutamente falsa, la que publicó Manuel del Arco (1969: 67-71) con un tal Boris Smyslov. Le presenta como un enviado del Gobierno de la Unión Soviética: por entonces no mantenía relaciones diplomáticas con España, pero ya corrían rumores de que los acercamientos comerciales podían desembocar en el intercambio de embajadores. Un día hace aparecer al tal Smyslov buscando solares en Barcelona en los que instalar unas oficinas de su país. Después de varios pases de florete le espeta:

“- ¿Desean ustedes normalizar las relaciones con nosotros para desalojar de nuestro suelo posibles rivales, en un conflicto mundial?

- Nuestra política es la paz; pero también impedir que el dólar se adueñe del mundo, con el disfraz de la protección. Los capitales norteamericanos colocados en países no fuertes, son Gibraltares de signo económico, más peligrosos que una roca que no tiene ningún valor estratégico y que resulta insultante para el pueblo español. Nuestro país no es rico, pero puede invertir dinero en las industrias de ustedes que necesitan seguir produciendo y a las que les falta consumidores, en tanto Rusia es una inmensa población, ya con capacidad adquisitiva. Usted que nos visitó, pudo advertir que, sin perder el sentido ideológico, medio siglo de un régimen ha permitido elevar el nivel de vida" (Arco, 1969: 70).

Todo esto cuando años atrás había escrito lo que sigue: "Soy enemigo y me parece una falsedad indigna de un periodista poner en labios de alguien frases que no haya pronunciado. Y mucho más censurable es inventarse un personaje" (Arco, 1960a: 413). Justificará este juego en la introducción al libro que lo reproduce:

- Presumes de ser veraz. Sin embargo, te inventaste un Boris Smyslov que ¡menudo jaleo armaste! Y hasta confusión en las Cancillerías

- Lo reconozco. Fue una inocentada. El 28 de diciembre me permito esa licencia, en forma de broma, que puede ser verdad. Pero, por única vez en mi vida dije 'entrevista en exclusiva'. Quien la reprodujo, y cayó en el engaño, procedió mal, porque si era en exclusiva debió pedir permiso para reproducirla. Al no hacerlo, en su pecado llevó la penitencia (Arco, 1969: 7).

La popularidad de estas intervenciones hizo que, como decíamos antes, se trasladara a la escritura creativa. Para no demorarnos en un centón de títulos diré que el periodista Mariano de Cavia escribió Despachos del otro mundo, interviús en directo con muertos ilustres ${ }^{8}$; que Giovanni Papini compuso Gog con supuestas entrevistas con Mahatma Gandhi, Albert Einstein, Lenin o Freud; que Juan Bonet reunió en En-

8 Mariano de Cavia escribió un reportaje sobre un incendio devastador en el Museo del Prado (El Liberal, 25 de noviembre de 1891). Centenares de madrileños corrieron a intentar sofocar las llamas, sin percatarse de no era cierto lo que allí se exponía. Muchos han considerado que se trataba de un aldabonazo necesario para atajar el desastroso estado en que se encontraba nuestra principal pinacoteca. Sólo al final del texto confesaba que era inventado de principio a fin y lo hacía con estas palabras: "Amigo y Director: Creo que, para ser esta la primera vez que ejerzo de reporter, no lo hago del todo mal. Ahí va, en brevísimo extracto, la reseña de los tristes sucesos... que pueden ocurrir aquí el día menos pensado". 
trevistario (1976) una serie de textos que habían sido divulgados en la revista humorística Don José y en el diario Baleares, lo que justifica con estas palabras: "Para atar un poco mi colaboración, propuse una especie de sección fija y se me ocurrió esto de las 'entrevistas falsas' - género que cuenta con una indudable tradición literaria, ahí está el Gog-y comencé a fabricarlas" (Bonet, 1976: 10). El autor "conversa" con Ramón Llull, Unamuno, Chejov, Georges Sand...

Con esto llegamos a nuestros días. ¿Hay todavía entrevistas ficticias? ¡Cómo no iba a haberlas! Un periodista bien conocido entre nosotros es Víctor Márquez Reviriego, quien se ha convertido en un perfecto especialista en ellas. La broma empezó en el semanario Tribuna hacia 1993, con una sección que se titulaba "Auténticas entrevistas falsas". Por allí desfilaron los prohombres del momento: Adolfo Suárez (17 de mayo) o Alfonso Guerra (31 de mayo). Durante varios años sus textos fueron apareciendo al final de cada número. La revista cerró y años más tarde su autor trasladó la sección al mensual Leer. También cada número contiene una entrevista fingida y hace un par de años recopilaba este material en su libro Auténticas entrevistas falsas ${ }^{9}$. Allí reconstruye la personalidad de Cervantes, Julio Verne, Gregorio Marañón o Stefan Zweig con las respuestas que posiblemente darían, puesto que se basa en un conocimiento exhaustivo de su trayectoria y escritos.

Hay que decir que ese título no es original de Víctor Márquez, puesto que el primero en emplearlo fue un periodista radiofónico que respondía al seudónimo de Oberón. En "Cabalgata Fin de Semana" simulaba unas entrevistas con los deportistas más destacados de la jornada y al fin acabó por publicar una selección de estos supuestos encuentros. No era fácil conseguir una imitación de las voces y de las ideas más frecuentemente expresadas por dichas figuras, pero el caso es que tuvo éxito con esta iniciativa, muy bien acogida por los oyentes.

No, no es difícil encontrar más muestras de este subgénero. En el suplemento Alfa y Omega se incluía el 12 de octubre de 1996 una "Entrevista con la Madre Teresa de Jesús", debida a la pluma del ilustre escritor José López Rubio y en las páginas que el diario $A B C$ dedica a la Comunidad Valenciana se incluían unas "Entrevistas desde el más allá", preparadas por Carlos Marzal. Por ejemplo, el 6 de febrero de 2011 conversaba con Gutenberg y el 11 de febrero de 2012 con Maimónides. El primero era presentado de esta manera: "Nuestro corresponsal en los consulados del más allá entrevista al inventor de la imprenta de tipos móviles, y le pregunta por el futuro del libro tradicional y de los e-books". A veces se utilizan párrafos textuales de los escritos de un personaje para confeccionar un texto de esta naturaleza. Es lo que hizo Lluís Vergés cuando quiso presentar a Albert Camus ${ }^{10}$ : "Casi no hace falta advertir al lector que está a punto de iniciar la lectura de un diálogo ficticio y de creación, en el que, no obstante, son absolutamente auténticas todas las citas del escritor franco-argelino". Para corroborar esta afirmación, en la página que ocupa este texto se incluye un re-

9 Los textos se acompañan de una "presentación verdadera", debida a José Bono, y un "auténtico prólogo falso" de Pío Baroja.

${ }^{10}$ Lluís Vergés: "Camus, más allá de su siglo", en el diario Menorca, 21 de octubre de 2013, p. 18. 
cuadro en el que se especifica de dónde proceden las citas que han sido puestos en la boca del escritor.

No conocemos que se haya publicado ninguna entrevista imaginaria con el Rey Juan Carlos, con la reina Sofía o el príncipe Felipe (títulos que cambiaron el pasado mes de junio, como es sabido), pero sí tenemos constancia de una que se publicó en un diario de Baleares con Isabel Sartorius en los tiempos en que se decía que mantenía una relación sentimental con el Príncipe (firmada por Marta Zoreda el 17 de julio de 1990). El tono humorístico que se desprende de su lectura sería suficiente para senalar a los lectores que se encuentran ante una simple broma, algo que viene acentuado por los titulares y el tono del texto. Lo vemos reproducido en una biografía de aque1la que se publicó poco después (Gracia, 1991: 96-99).

María Teresa Campos, popular presentadora de televisión, lanzó a finales del año 2012 su libro Princesa Letizia, compuesto con las supuestas opiniones personales que va desgranando esta y que se presenta como "una historia ficticia basada en hechos reales". Se trata de un ejercicio de imaginación, que explica de la siguiente manera: "Lo único que he hecho es pensar qué pensará ella, ponerme en su lugar partiendo de su personalidad y de todo lo que los periodistas conocemos de alguien sobre el que se ha escrito mucho"11. No se sabe que esta ficción, explicada una y otra vez, escandalizara a nadie.

\section{No existe engaño}

Y así llegamos al momento en el que el semanario Diez Minutos incluía una entrevista fingida con la entonces princesa de Asturias, Letizia Ortiz, ahora ya reina de España. En modo alguno hay un intento de engañar a los lectores, cuando se destaca que nos hallamos ante una entrevista imaginaria; que se trata de una recreación de una conversación que podía haber tenido lugar, que "con informaciones y datos recogidos durante los últimos años, hemos imaginado una charla con ella, una entrevista improbable con respuestas reales". Añade como demostración de sinceridad que "en un alarde de osadía nos hemos lanzado a entrevistar a la Princesa de manera figurada. Porque sabemos tanto de ella a través de terceros, medios de comunicación y testimonios directos que nos atrevemos a suponer lo que nos contestaría si tuviéramos un café (para ella té) y una grabadora delante".

Enseguida comienza la supuesta conversación, con las preguntas y respuestas que podrían ser las esperables en un caso así:

- Señora, diez años como Princesa de Asturias. ¿Qué definiría como lo mejor y como lo peor de estos años junto a su marido?

- Me quedo con mi servicio a España, con el trabajo que día a día intento mejorar para servir a mi país y a los españoles junto al Príncipe, que me ha enseñado cómo llevar a cabo mis tareas. También mis dos hijas (ríe), aunque el Príncipe dijo el día de nuestra pedida de mano que tendríamos entre tres y cinco. Y lo peor, la pérdida de gente querida [...].

- Todos hemos observado a lo largo de este tiempo que su marido y usted funcionan como un tándem preciso. Pero también que tienen personalidades contrapuestas y a veces muy alejadas.

11 "María Teresa Campos: 'No ha nacido aún el que me diga a mí qué pregunta tengo que hacer", en el diario La Vanguardia, 5 de diciembre de 2012. 
- No hay por qué negar algo que les sucede a muchas parejas y que, sin embargo, no afecta a su nivel de compromiso ni a sus afectos. El Príncipe es calmado, reflexivo, moderado, equilibrado..., valores que le han inculcado desde niño y que han forjado un carácter de hombre tranquilo. Yo soy más apasionada, impaciente, inquieta, nerviosa, discutidora... Pero nos compenetramos bien. Él me escucha a mí y yo aprendo de él. Nos admiramos mutuamente.

Podríamos seguir reproduciendo el contenido de este texto y concluiríamos que se trata de unas respuestas lógicas, respetuosas, que no se salen del guion de lo que han sido sus palabras hasta ahora o de lo que se supone que opina. Aquí no hay humor ni caricatura, sino un conocimiento de lo que ambos han manifestado en las contadas ocasiones en que se han referido a cuestiones personales. De hecho, la persona a la que se le encomendó especialmente redactarlo (porque posiblemente hayan intervenido varias) está acostumbrada a seguir los pasos de la familia real y posee un nivel de información de sus actividades y pensamientos que no están al alcance de cualquiera. Podrá gustar más o menos el resultado, pero en cualquier caso los lectores han sido avisados del planteamiento inicial y la redacción es sumamente fiel -al menos en líneas generales, por lo que sabemos-a las ideas que se manejan en aquella Casa.

Sorprende, por tanto, que el diario El País ofrezca a sus lectores un suelto (especie de editorial menor, bajo el epígrafe de "El Acento") con el título de "Entrevistas inventadas" (17 de junio, p. 30), con un tono condenatorio. Tras unas referencias a la manipulación que denuncia la película "Ciudadano Kane" y que es voz común que practicaba William R. Hearst, recuerda a Diez Minutos el viejo dicho "No dejes que la realidad te estropee un buen reportaje". Nada que alegar hasta el momento, pero sí cuando comienza a aplicar esta doctrina al semanario por haber publicado una entrevista ficticia con la princesa Letizia: "Siguiendo esta técnica, la semana que viene podrían sorprendernos con una entrevista a Obama o al papa Francisco. Llegando al esperpento, podrían recrear una conversación con Cristóbal Colón o con Alejandro Magno". Desde luego, si tal hicieran no sería una novedad, sino una manida imitación de lo que otros hicieron en el pasado ${ }^{12}$.

Ante semejante severidad en la reconvención habría que pensar que El País no ha caído jamás en semejante error y ahí es donde su ignorancia e inconsecuencia se acentúan, porque claro está que ha publicado este tipo de textos en más de una ocasión: casi cuarenta años de vida suman cientos de miles de páginas y millones de informacio-

${ }^{12}$ Efectivamente, son varios los libros que hemos conocido con contenidos semejantes, porque están compuestos con entrevistas fingidas a personajes históricos. Así, el de Jesús García Sánchez: Entrevista con la historia. Madrid, Biblioteca Cultural de RTVE, 1976 (con Nerón, Enrique VIII de Inglaterra, Lope de Aguirre o Winston Churchill); Óscar Gómez Ortega: Entrevistas con la historia. Madrid, Bosque de Palabras, 2007 (con Alejandro Magno, Mozart, Stalin o Ghandi); José A. Navarro Gisbert: Entrevistas con la historia. Madrid, Áltera, 2010 (con Carlos I, Felipe II o Hernán Cortes)... Añadamos, aunque resulte innecesario, que el libro de Oriana Fallaci con el mismo título no se encuentra en la línea de los anteriores, porque su contenido responde a entrevistas reales con personajes relevantes del momento en que fueron publicadas. 
nes de todo tipo, en las que no están ausentes estas de las que abominan. No vamos a recorrerlas una a una, pero no es difícil encontrarnos con textos que contradicen su adusto planteamiento editorial. Hace unos años, por ejemplo, se dedicaba una página entera al colaborador del periódico y director de cine Gonzalo Suárez para que diera a conocer una "entrevista imaginaria" con Groucho Marx ${ }^{13}$. Aparte del antetítulo donde se anuncia de esta manera, el comienzo no deja lugar a dudas: "Esta semana se han comenzado a reponer en España algunas de las películas más conocidas de los hermanos Marx. El cielo [sic] ha comenzado con 'Una noche en Casablanca' [...]. Un escritor y cineasta español, Gonzalo Suárez, asistió a la muerte de Groucho con la rabia del creador que se resiste a perder a su personaje. Aquel encuentro con la imagen de Groucho le sirvió para establecer una conversación imaginaria que mantuvo inédita hasta hoy. Esta conversación falsa ilustra...". No creo que nadie se escandalizara al echarse a la cara este texto ni lo tildara de atrevimiento indebido.

Más casos. El País tiene como colaborador al humorista Joaquín Reyes. En la Revista de Agosto del año 2006 mantuvo la sección "Viajes inventados". Uno de los días aparece una supuesta charla con un mafioso ${ }^{14}$. En ningún momento se dice que en realidad no ha tenido lugar, pero esa alusión a que nos sintamos ante algo inventado y el contexto humorístico son más que suficientes para que lector se haga su propia composición de lugar. No es el caso de un texto del mismo autor que se publicaba apenas una semana después de aquel suelto recriminatorio y burlón. Aquí se habla de "entrevista surrealista", adjetivo que tiene unas connotaciones de rareza, pero no de fingimiento ${ }^{15}$. ¿Cómo interpretar, entonces, la supuesta conversación que el autor mantiene con Melanie Griffith, ex pareja del español Antonio Banderas? No hace falta ser un profesional del periodismo para tener la certeza que el colaborador y el periódico juegan interesadamente a la ambigüedad. En puridad habría que aplicar aquí lo que pontificaba ese diario el pasado 17 de junio: "Nada impide que se publiquen conversaciones irreales con personajes reales. Pero para estos contenidos, que son invenciones y fabulaciones, están las novelas, las revistas de humor o los programas televisivos [...]. Que un medio que se dice informativo -y que por tanto debe regirse por la veracidad de sus noticias- eche mano de estas técnicas es algo que chirría. Se ve con demasiada frecuencia en los medios con tendencia a la frivolización y banalización". Pues depende de cómo se enfoquen los contenidos.

\section{Entrevistas falsas y entrevistas fingidas}

Es necesario diferenciar claramente entre entrevistas falsas y entrevistas fingidas. Las primeras, cuando se hace pasar por verdadero lo que es pura invención, sin ningún tipo de advertencia al lector, son inaceptables. En realidad no es periodismo, porque este se basa en la verdad y no en la mentira. Las entrevistas fingidas, en las que desde el primer momento se deja claro al lector que se trata de una suposición, es una especie

${ }^{13}$ Gonzalo Suárez: “Groucho Marx, el movimiento no tiene autor”, en El País, 9 de abril de 1982.

${ }^{14}$ Joaquín Reyes: “¿Quién te envía?”, en El País, 11 de agosto de 2006.

15 Joaquín Reyes: "Melanie Griffith", en el suplemento "S Moda" de El País, 28 de junio de 2014, p. 13. 
de juego. En unos casos para exponer con palabras tomadas de sus textos o de ideas expresadas con anterioridad lo que está en la línea del personaje; en otros, para exagerar sus puntos de vista y derivar hacia la sátira o el humor. Ambas direcciones se han practicado con frecuencia, como hemos visto, y no tiene ningún sentido hacer ascos a esta práctica que ni engaña a los lectores ni perjudica a los que se imita de manera inteligente. Los periodistas que se escandalizan ante una muestra tan honesta y respetable como la de Diez Minutos lo que ponen de manifiesto es su ignorancia ante una práctica absolutamente consolidada en los medios escritos de nuestro país.

Dos miércoles consecutivos de principios de julio se reunió la citada Comisión de Arbitraje, Quejas y Deontología, presidida por el catedrático Núñez Encabo y de la que forman parte tanto periodistas como juristas. La discusión partió de una propuesta de resolución aportada por el catedrático emérito José Luis Martínez Albertos solo atendida en parte, según parece, puesto que este no veía mayores dificultades en aceptar que se publicara una entrevista fingida con la princesa Letizia, dada la tradición en este sentido en la prensa española y el hecho de que la presentación insistiera en que se trataba de una "entrevista imaginaria", con lo que no cabe el engaño.

Sin embargo, el documento final (2014/95, de 16 de julio) se muestra contrario a esta práctica, pues concluía con las siguientes palabras: "Por lo expuesto, desde la defensa de la libertad de expresión, así como de la necesidad de velar por la calidad y credibilidad del periodismo y a partir de que la primera exigencia del periodismo es el respeto a la verdad, sin tergiversación o deformación, no nos hallamos ante una buena práctica periodística, pues el método de esta entrevista imaginaria, no tiene la misma garantía de veracidad que una entrevista real con la persona concernida. Además puede también afectar al derecho a la intimidad y la propia imagen, a la que la persona presuntamente entrevistada tiene derecho, aunque sea un personaje público" (el texto íntegro lo ofrecemos como Anexo).

\section{Datos de una encuesta}

Por último y como curiosidad, diremos que cuando se publicó esta entrevista imaginaria, en las redes sociales se desarrolló una elevada actividad, con comentarios de todos los signos, aunque abundaban los negativos. Hemos querido hacer la prueba de averiguar cuáles eran las opiniones de un grupo seleccionado de personas jóvenes: una porción de alumnos nuestros de Periodismo. Con este fin añadimos una pregunta sobre el tema en el examen extraordinario de Redacción Periodística II (julio de 2014), que es cursada por estudiantes de tercer año, a los que durante el curso se les había explicado la entrevista y en algún momento también la fingida, entre el resto de modalidades. Las conclusiones y los juicios más relevantes que hemos extraído han sido resumidos y figuran a continuación.

La pregunta era la siguiente: "En las últimas semanas se ha hablado de un entrevista fingida que ha sido publicada en una revista española. ¿La conoce? ¿Qué le sugiere?”

De las respuestas hemos sacado los siguientes datos y opiniones de interés:

1. El tema se suscitó ante 47 alumnos, pero solo respondieron 18 (lo que representaba el 38 por ciento del total). Hay que deducir que el resto (62 por ciento) no tuvo noticia de este hecho o que tal publicación no le sugiere nada. 
2. La pregunta llevaba implícita el citar el nombre de la revista, pero seis (el 33\% de los que respondieron) no supieron decirlo. El resto nombra diversas cabeceras, donde asegura que se publicó, como Hola (seis, el 33\%), Lecturas (cuatro, el 22\%), Semana (uno, 6\%) y Veinte Minutos (!!!) (uno, el 6\%). Sólo uno de los encuestados acertó con el nombre de la revista: Diez Minutos.

3. Cuatro alumnos (el 22\%) atribuyen la publicación de la entrevista al hecho de su proclamación como reina, cuando es sabido que se trataba de celebrar los diez años transcurridos desde su boda con don Felipe. En esa fecha no se había producido la abdicación de Juan Carlos I.

4. De todos los que tuvieron conocimiento de este texto, doce alumnos (el 67\%) se manifiestan contrarios a que se publique una entrevista ficticia con la princesa. Sólo uno de ellos manifiesta una opinión positiva (el 6\%) y cinco no se pronuncian, pues solo aportan una explicación sobre esta clase de entrevistas.

5. De las dieciocho respuestas recibidas hemos seleccionado algunos fragmentos que tienen interés por la contundencia de la opinión expresada:

- "Por mucho que se haya aclarado su carácter ficticio y que sea un género que se ha dado anteriormente y que es reconocido como tal, para mí no tiene demasiado sentido [...]. Yo lo considero una especie de ataque al ejercicio periodístico y también me parece ligeramente desconsiderado con la persona que está siendo 'ficticiamente' entrevistada".

- "Lo impactante es que aún sabiendo con total seguridad que se trataba de una entrevista falsa y sin ningún grado de credibilidad, a la gente le interesaba saber qué era lo que contestaba Letizia, como si se tratase de unas declaraciones totalmente salidas de la Princesa de Asturias. No me sorprende que algo así, tan malo para el periodismo, se haga, ya que en el mundo del corazón solo trabajan y se interesan en personas que no son nadie, que llegan a la fama por sus historias amorosas y escándalos públicos".

- "Me produce rechazo y no leería una entrevista fingida referida a un personaje público y que puede ser entrevistado. Me sugiere que no han realizado su trabajo como deberían haber hecho".

- "La noticia resultó cuanto menos impactante, ya que es un género prácticamente en desuso y el público no está acostumbrada a ella. La publicación desató las críticas en las redes sociales que se preguntaba si todo valía. Personalmente me resultó algo surrealista y anecdótico".

- "Me sugiere que es muy acertada, ya que mucho se ha hablado de ella desde su enlace $[\ldots]$ No me parece una entrevista fingida con ánimo de burla u ofensa, más bien un guiño a toda su trayectoria".

- "Este tipo de entrevista sirve para informarse de las opiniones (pues el autor se documenta como si fuera una de verdad). En ningún caso es falsa, pues no sería periodismo. Su intención es entretener".

- "Esta publicación emitida en la revista de prensa del corazón española ha causado gran revuelo y expectación, debido a que en la actualidad este género está casi desapareciendo. Hace mucho que se dejaron de elaborar debido a la poca seriedad que atesoran".

- "Independientemente del respeto y el interés que me produce el género, creo que en este caso ha sido utilizado de forma engañosa, para confundir al lector. Además de no aportar ninguna información novedosa, el propósito de este subgénero de la entrevista, que es el de entretener (yo diría que de forma inocente), queda relegado para dar paso a la simple mercantilización de un producto informativo, a través de una portada que puede llevar a engaño por su estética o a la repercusión mediática". 
- "No me gusta este tipo de entrevistas. Aportan mucho interés al lector, pero a la vez le engaña, ya que habla de algo que no ha dicho el entrevistado".

- "Toda la reputación que había alcanzado la revista en tiempos pasados, ha caído en picado con este hecho. El ansia por buscar morbo y que se dispare el número de ventas, lleva a la pérdida de credibilidad. El lector sentirá ahora cierto recelo y se mostrará reacio a creer en la veracidad de otras entrevistas que sí han existido".

Mi interpretación personal es que la lectura de periódicos se encuentra bajo mínimos, incluso entre un grupo selecto en este campo. Si tienen referencia de ciertas noticias es porque su eco les llega a través de las redes sociales, de lo cual se deduce que no tienen constancia completa de lo que ha ocurrido (ni han bebido en las fuentes primarias ni han contrastado las informaciones a las que han tenido acceso). El conocimiento obtenido es resumido, fragmentario y está condicionado por el tono de los comentarios que les llegan desde la pantalla de sus amigos, incluso por parte de personas desconocidas que, probablemente con nulo saber y con una carencia lamentable de criterios, opinan y envían lo primero que se les ocurre. Unos estudiantes de periodismo deberían mantenerse al margen de utilizar una información de una manera tan banal como aquí se aprecia, pero mucho nos tememos que se trata de una realidad cada vez más enraizada y extendida.

\section{Referencias bibliográficas}

ARCO, Manuel del (1960a): "La interviú", en GONZÁLEZ RUIZ, Nicolás (dir): El periodismo. Teoría y práctica. Barcelona, Noguer, pp. 413-414.

ARCO, Manuel del (1960b): Los personajes son de carne y hueso. Barcelona, Planeta. ARCO, Manuel del (1969): Hablar con ton y son. Barcelona, Planeta.

BALSEBRE, Armand; MATEU, Manuel; y VIDAL, David (1998): La entrevista en radio, televisión y prensa. Madrid, Cátedra.

BONET, Juan (1976): Entrevistario. Barcelona, Ediciones 29.

CAMPOS, María Teresa (2012): Princesa Letizia. Barcelona, Planeta.

CANTAVELLA, Juan (2002): Historia de la entrevista en la prensa. Madrid, Universitas.

CANTAVELLA, Juan (2007): Manual de la entrevista periodística. Madrid, Universitas ( $3^{\mathrm{a}}$ edición).

ECHEVARRÍA, Begoña (2002): Las W's de la entrevista. Valencia, Universidad Cardenal Herrera-CEU.

GONZÁLEZ-RUANO, César (2002): Obra periodistica (1925-1936). Edición de Miguel Pardeza. Madrid, Fundación Cultural Mapfre Vida.

GRACIA, Fernando (1991): Isabel Sartorius. Casi una reina. Madrid, Temas de Hoy. MÁRQUEZ REVIRIEGO, Víctor (2012): Auténticas entrevistas falsas. Madrid, Leer.

OBERON (1953): Auténticas entrevistas falsas. Prólogo de Bobby Deglané. Epílogo de Tip y Top. Madrid, Alhambra. 
PAPINI, Giovanni (1931): Gog. Traducción y prólogo de Mario Verdaguer. Barcelona, Apolo.

RODRÍGUEZ BETANCOURT, Miriam (2001): La entrevista periodística y su dimensión literaria. Madrid, Tauro Producciones.

RODRÍGUEZ VILAMOR, José (2000): Redacción periodística para la generación digital. Madrid, Universitas.

\section{Anexo: Resolución 2014/95 de la Comisión de Arbitraje, Quejas y Deontología del Periodismo (FAPE)}

Sobre la vulneración del compromiso con la búsqueda de la verdad, que obliga al periodista a informar sólo sobre hechos de los cuales conozca su origen, sin falsificar documentos ni omitir informaciones esenciales, así como a no publicar material informativo falso, engañoso o deformado (art. 13 del Código Deontológico). Dicha vulneración pudo haber sido cometida por la revista Diez Minutos en su número 3.275, de fecha 28 mayo de 2014, por la difusión de una entrevista imaginaria con Doña Letizia Ortiz, en aquellas fechas Princesa de Asturias.

La Comisión de Arbitraje, Quejas y Deontología de la Federación de Asociaciones de Periodistas de España (FAPE), acoge la solicitud presentada por el Colegio Oficial de Periodistas de la Región de Murcia y considera que el tratamiento informativo utilizado por la citada publicación no constituye una buena práctica periodística, pues no tiene la misma garantía de veracidad que una entrevista real con la persona concernida. Además puede también afectar al derecho a la intimidad y la propia imagen, a la que la persona presuntamente entrevistada tiene derecho, aunque sea un personaje público.

\section{SOLICITUD}

El Colegio Oficial de Periodistas de la Región de Murcia, corporación de derecho público que tiene encomendada la defensa de los intereses generales de la profesión periodística en su ámbito territorial, con fecha 23 de mayo de 2014 cursó a la secretaría de la Comisión de Arbitraje, Quejas y Deontología de la FAPE una solicitud en la que pide un informe-resolución sobre la posible vulneración de principios deontológicos por parte de la revista Diez Minutos como consecuencia de la publicación de una entrevista ficticia con la princesa. El reportaje en cuestión ocupa la portada con el título "LETIZIA la Princesa cumple 10 años", seguida de dos sumarios también en portada: "Entrevista imaginaria: recreamos con datos contrastados y testimonios fiables la conversación que podría haber tenido con nuestra revista"; "Las 20 imágenes más comentadas desde que se casó con Felipe el 22 de mayo de 2014". La pieza periodística continúa en cuatro páginas interiores, desde la 10 a la 13. El texto aparece firmado con las iniciales D.M. (es decir, Diez Minutos), lo que hace presumir que se trata de un trabajo en equipo de la redacción.

\section{HECHOS DENUNCIADOS}

En su solicitud de apertura de expediente, el Colegio Oficial de Periodistas de la Región de Murcia denuncia a la revista Diez Minutos por la utilización de una entrevista falsa con Doña Letizia, que califica como un "ejercicio de ficción" que ha generado hilaridad en numerosos comentarios de las redes sociales. Pero, al mismo tiempo, el desprestigio no ha dañado única- 
mente a dicha publicación, sino también a todo el conjunto de la profesión, ya que bastantes de estas opiniones -dice el citado Colegio- consideran este incidente como una prueba más de la actual crisis del periodismo: "si no tienes la entrevista con el personaje popular de turno, te la inventas".

\section{DOCUMENTOS QUE ACOMPAÑAN A LA DENUNCIA}

- Copia de las páginas de Diez Minutos en las que aparece inserta la entrevista imaginaria con la princesa.

- Copia de una página del diario La Vanguardia (22 mayo 2014) en la que se hace referencia a este asunto.

\section{NORMAS DEONTOLÓGICAS QUE EL DENUNCIANTE CONSIDERA VULNERA- DAS}

En su queja, el Colegio Oficial de Periodistas de la Región de Murcia considera que la actuación llevada a cabo por la citada revista "opera en descrédito del periodismo y vulnera principios generales de la deontología profesional". De esos principios éticos señala estos dos: el respeto a la verdad y el deber de difundir con honestidad la información.

\section{ALEGACIONES DEL DENUNCIADO}

La directora de Diez Minutos, doña Cristina Acebal -como respuesta a la carta enviada por el Secretario de la Comisión en la que se le comunicaba la apertura de expediente y se le invitaba a presentar alegaciones ante la queja formulada contra la publicación (art. 9.6 del Reglamento)-, defendida en este caso por el Letrado del ICAM don Tomás A. Ridruejo, presentó dentro del plazo indicado un voluminoso escrito cuyos aspectos más destacados son los siguientes:

- El Colegio Oficial de Periodistas de la Región de Murcia no está legitimado para presentar esta solicitud de expediente: la solicitud aparece sin firma alguna que la respalde y tampoco queda justificada la representación profesional que dicho colegio se atribuye.

- En esta solicitud tampoco se indica cuáles son los preceptos que ha infringido la directora de la publicación.

- No hay legitimación activa por parte del Colegio Oficial porque los periodistas murcianos no son mencionados por la revista ni la entrevista les afecta a ellos de ningún modo.

- No ha habido "alarma social" que justifique el inicio de un procedimiento por incumplimiento de las normas deontológicas.

- La utilización de "entrevistas imaginarias" es una práctica bastante habitual entre los medios de comunicación, escritos, audiovisuales y digitales. Incluso hay publicado en España un libro, titulado Princesa Letizia, original de la periodista María Teresa Campos, en el que todo es una entrevista imaginaria.

- Para demostrar el aserto de que estas entrevistas son bastante habituales en los medios periodísticos, tanto en el pasado como en el momento actual, la directora de Diez Minutos aporta un total de 25 documentos con muestras de entrevistas imaginarias difundidas en España y firmadas por destacados profesionales: María Teresa Campos, Víctor Márquez Reviriego, Antonio Burgos, etc., además de otros textos aparecidos en blogs más o menos anónimos. 
- El documento núm. 26 es un dictamen del Catedrático de Periodismo en la Universidad San Pablo-CEU, don Juan Cantavella, donde se analiza desde una doble perspectiva (diacrónica y sincrónica) la presencia de las entrevistas imaginarias en los medios de comunicación. Para concluir con las siguientes contundentes palabras: "Los periodistas que se escandalizan ante una muestra tan honesta y respetable como la de Diez Minutos lo que ponen de manifiesto es su ignorancia ante una práctica absolutamente consolidada en los medios escritos de nuestro país".

Y a la vista de todos los argumentos expuestos en su escrito, la directora de la revista solicita a la Comisión de Arbitraje "inadmitir o bien desestimar la petición-solicitud" efectuada contra ella por el Colegio Oficial de Periodistas de la Región de Murcia.

\section{PRUEBAS PRACTICADAS}

La Ponencia analizó la entrevista que ha dado origen a este recurso, así como algunas de las reacciones que ha provocado en algunos medios de comunicación: La Vanguardia, El País, Efe, El Confidencial, etc. Se ha tenido en consideración el dictamen que acompaña al escrito de alegaciones.

\section{RAZONAMIENTOS DE LA PONENCIA}

A. La Ponencia, de acuerdo con la decisión previa de la Comisión Permanente, considera que el Colegio Oficial de Periodistas de la Región de Murcia está legitimado para interponer el recurso que nos ocupa. Frente a lo argumentado por la directora de Diez Minutos, entendemos que en la solicitud de expediente el peticionario indica cuáles son las normas que considera vulneradas, aunque no señale el número concreto de cada artículo; la vulneración del "respeto a la verdad" nos remite al art. 2 del Código de la FAPE, mientras que el quebrantamiento del "deber de difundir con honestidad la información" hace referencia al art. 3 del mismo texto.

B. Desde el punto de vista de la Redacción Periodística, la entrevista imaginaria es un tipo de entrevista, asentada en la literatura periodística, e incluso un subgénero de la misma. Es un género literario periodístico, que se inspira, e incluso recrea la forma, estructura y estilo de la entrevista, sin serlo. Esta Comisión conoce el significado periodístico de las entrevistas simuladas y ficticias y cuenta en su seno con un reconocido especialista en Redacción Periodística. Aunque se ha tenido en cuenta el significado de la entrevista imaginaria, como ejercicio de Redacción Periodística, las opiniones divergentes, en cada caso, no deben ser objeto de calificativos despectivos. Hay otros puntos de vista a considerar, especialmente el ético y deontológico. Independientemente de la casuística de las diversas citas de entrevistas que se exponen en las alegaciones, cada caso debería ser analizado en su singularidad, lo que no corresponde en estos momentos a nuestra Comisión, que debe pronunciarse únicamente sobre la singularidad del caso objeto de la demanda.

C. Desde el punto de vista deontológico, que como se ha dicho debe ser el prevalente en el ámbito propio de esta Comisión, "la recreación de datos contrastados" en la entrevista imaginaria, que son en realidad fragmentos tomados en momentos y ocasiones diferentes, colocados a continuación de preguntas a las que se ajustan contestaciones, está fuera del contexto temporal propio de una entrevista publicada en la fecha 28 de Mayo, que dé sentido actual y común a todas ellas, evitando el riesgo de su tergiversación y la vulneración del artículo 13 del 
Código Deontológico de la FAPE: “omitir informaciones esenciales, así como no publicar material informativo deformado".

En consecuencia, no estamos ante una buena práctica deontológica del periodismo. Este recurso, para este caso concreto u otros análogos, no se adecua a las exigencias éticas y debería evitarse para que no sea una práctica habitual del periodismo.

Sin perjuicio de que los criterios de la presente resolución sean aplicables a supuestos análogos al presente, esta Comisión prefiere dejar para un momento futuro la emisión de un informe sobre la cuestión planteada por el Colegio Oficial de Periodistas de la Región de Murcia, acerca de la procedencia de que en publicaciones de naturaleza informativa se utilicen géneros periodísticos para elaborar ficciones.

\section{RESOLUCIÓN}

Por lo expuesto, desde la defensa de la libertad de expresión, así como de la necesidad de velar por la calidad y credibilidad del periodismo y a partir de que la primera exigencia del periodismo es el respeto a la verdad, sin tergiversación o deformación, no nos hallamos ante una buena práctica periodística, pues el método de esta entrevista imaginaria, no tiene la misma garantía de veracidad que una entrevista real con la persona concernida. Además puede también afectar al derecho a la intimidad y la propia imagen, a la que la persona presuntamente entrevistada tiene derecho, aunque sea un personaje público.

Madrid, 16 de julio de 2014. 